\title{
Temperature of a Copper Arc
}

\author{
Charles H. Corliss
}

\begin{abstract}
The temperature of a copper arc in air has been measured by comparing 31 sets of transition probabilities for spectra of 20 elements with spectral-line intensities from those elements separately added to the copper. The intensities are taken from the recently published NBS Tables of Spectral-line Intensities and the transition probabilities from the literature. The individual determinations are discussed. The set of determinations is shown to follow a Gaussian distribution about a mean of $5100^{\circ} \mathrm{K}$. The average deviation of the determinations is $470{ }^{\circ} \mathrm{K}$ and the standard deviation of the mean is $110^{\circ} \mathrm{K}$. This temperature may be used in the evaluation of thousands of atomic transition probabilities from the intensities in the new tables. The effect of the uncertainty in the temperature on derived transition probabilities is evaluated as a function of excitation potential.
\end{abstract}

\section{Introduction}

Physicists have a natural interest in measuring quantities of extraordinary magnitude. This is especially true when the quantity measured permits new or more accurate evaluations of physical constants.

Such a quantity is the temperature of the electric arc in air between metallic electrodes. Well above the melting points of all materials and the boiling points of nearly all, the arc provides one of the hottest locations generally available in the physical laboratory. In such an arc it is possible to study the properties of atoms whose behavior is described by Boltzmann's law.

One particular arc, the temperature of which is especially interesting is the are between copper electrodes, in which the spectra reported in the NBS Tables of Spectral-line Intensities were excited [1]. ${ }^{1}$ It happens that the temperature of this are is susceptible of measurement by means of these very spectral-line intensity data. In itself, this would tempt us to carry out the determination; the fact that an accurate value of the temperature may enable us to evaluate transition probabilities for the 25,000 classified lines in the NBS Tables makes the temptation irresistible.

The arc has been described in the NBS Tables [1]. It was struck between two copper pellets $1 / 4$ inch in diameter, 1/4 inch long, and weighing 1.5 grams each. The pellets were formed in a hydraulic press at 5000 psi from fine copper powder. Two pellets were mounted in water cooled clamps, cathode above the anode, with an arc gap of $3 \mathrm{~mm}$. A direct current of 10 amperes, controlled by resistive ballast, was drawn from a 220-volt line. Exposures with which the spectra were taken varied in duration from $1 \mathrm{sec}$ to 5 min depending on spectrographic efficiency and photographic plate sensitivity in different spectral regions. Separate sets of spectrograms were made for each element, using for each exposure fresh pellets to which an element had been added in the proportion of 1 atom of the element for every 1000 atoms of copper. The element was thoroughly mixed with the copper powder before pressing.

\footnotetext{
1 Figures in brackets indicate the literature references at the end of this paper.
}

A lens at the slit of the spectrograph formed an image of the arc which fell entirely within the aperture of the grating, consequently the spectra represented radiation from all parts of the arc.

The method of temperature measurement adopted here is based on comparisons of published experimental transition probabilities of atomic lines with the intensities of the same lines measured in the copper arc. This method yields a temperature which is precisely that appropriate to the calculation of transition probabilities from our intensities.

If $N_{n}$ atoms in the arc column are in an excited state $n$, the number of transitions per second to a lower state $m$ will be $N_{n} A_{n m}$ where $A_{n m}$ is Einstein's probability coefficient of spontaneous emission [2]. The power from the transition is

$$
I=h \nu N_{n} A_{n m}
$$

where $I$ is the intensity of the emitted line, $h$ is Planck's constant, $\nu$ is the frequency of the line and $h \nu$ is the energy of a single photon. The temperature enters the comparison through its role of populating the upper level in accordance with Boltzmann's law

$$
N_{n}=N_{0} \frac{g_{n}}{g_{0}} e^{-\frac{E}{k T}}
$$

where $N_{0}$ is the population of the ground state and $g_{0}$ is its statistical weight $(2 J+1), g_{n}$ is the statistical weight of the upper level, $E$ is the energy of the upper level, $k$ is Boltzmann's constant and $T$ is the absolute temperature.

Substituting (2) into (1) we have

$$
I=\frac{N_{0}}{g_{0}} h \nu g_{n} A_{n m} e^{-\frac{E}{k T}} .
$$

Substituting $\nu=c / \lambda$, where $c$ is the velocity of light and $\lambda$ the wavelength of the line, and changing in to logarithmic form (base 10), (3) becomes

$$
\log \frac{I \lambda}{g_{n} A_{n m}}=\log \frac{N_{0} h c}{g_{0}}-\frac{0.434 E}{k T} .
$$

The first term on the right of (4) is a constant for 
any particular element in this arc. We set it equal to $C$ and solve for $T$. Introducing a value for $k$,

$$
T=-\frac{625 E}{\log \frac{I \lambda}{g A}-C}
$$

where $T$ is in ${ }^{\circ} \mathrm{K}, g A=g_{n} A_{n m}$ and $E$ is in units of $10^{3} \mathrm{~cm}^{-1}$ which we will call kilokaysers $(1 \mathrm{kK}=$ $1000 \mathrm{~cm}^{-1}$ ) in accordance with a suggestion of Meggers [3]. The value of $T$ is most conveniently obtained from a plot of $\log I \lambda / g A$ versus $E$ for each spectrum in which relative values of $g A$ are known. The constant $C$ does not affect the slope of the line from which $T$ is determined.

The ordinate is equivalent to $\log N_{n} / g_{n}$ so the plot is in effect a display of the population of excited levels in the atom as a function of the level value. Plots for eight sets of transition probabilities taken from the literature and compared with our intensities are given in figures 1 to 8 . The straightness of the plots clearly shows that the observations are in accord with the Boltzmann distribution. The population of levels of equal statistical weight declines exponentially with increasing energy values.

If the $f$-value is known instead of $A$, we may use Ladenburg's [4] equation

$$
g_{n} A_{n m}=\frac{8 \pi^{2} e^{2}}{m c} \frac{g_{m} f_{m n}}{\lambda^{2}}
$$

for converting eq (5) to the form

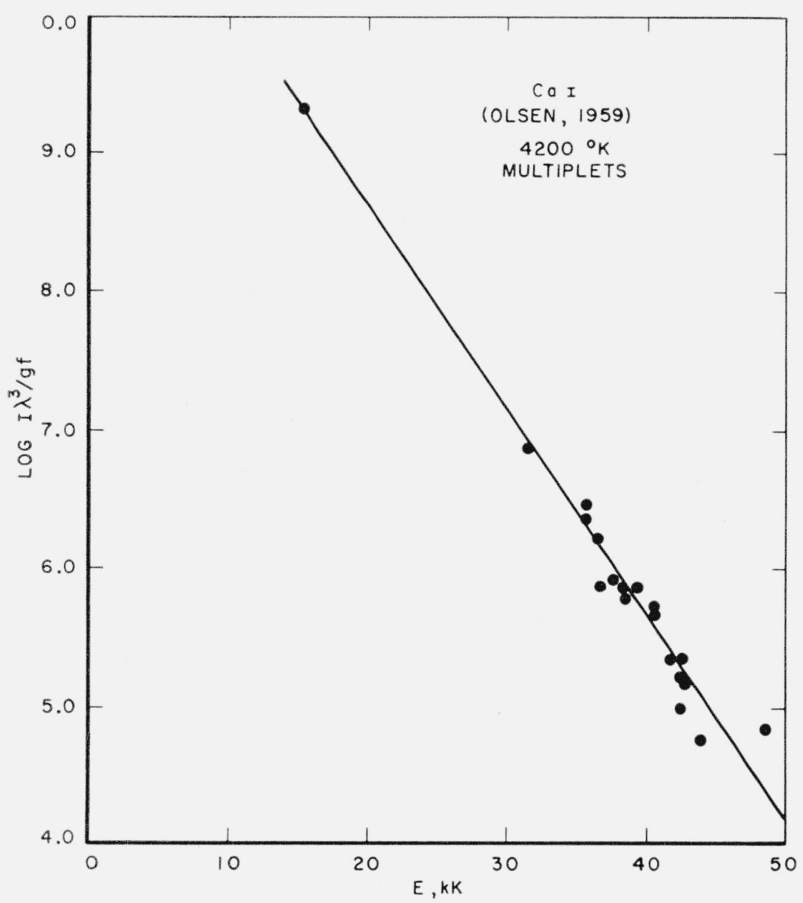

FIgURE 1. Log ratio of intensity $\times \lambda^{3}$ to gf-value for multiplets of $\mathrm{Ca} \mathrm{I}$ in the copper arc plotted versus upper level.

$\mathrm{An}$ arc temperature of $4200^{\circ} \mathrm{K}$ is derived from the slope of the line of best fit.

$$
T=\frac{-625 E}{\log \frac{I \lambda^{3}}{g f}-C^{\prime}}
$$

where $g f=g_{m} f_{m n}\left(=g_{n} f_{n m}\right)$, and $C^{\prime}$ is a constant.

We assume that the temperature of the arc was constant during the exposure of each of the hundreds of spectrograms in which our intensity observations were made. Great care was taken in the preparation of the electrodes and in the operation of the arc to insure uniformity in the experimental conditions from exposure to exposure. The NBS intensity data used in the 31 temperature determinations reported in section 4 of this paper are taken from about 50 separate exposures. It will be shown in the discussion that the variation in the determinations arises, at least in part, from systematic errors amongst the sets of transition probabilities.

\section{Excitation in the Arc in Air at Atmos- pheric Pressure}

The question arises whether we should be able to assign a valid temperature which can be used to describe the intensity of spectral lines emitted in accordance with eq (3). If there are several processes of excitation at work, each operating at a different effective temperature, then eq (3) is not valid. In a classical investigation, Ornstein and Brinkman [5] have shown that excitation in the column of the ordinary arc in air is controlled by collisions between atoms and molecules in a strictly thermal fashion. The same process is responsible for ionization and dissociation. They found that the excitation was well described by Boltzmann's law and that ionization followed Saha's equation, which also demands a thermal aggregation of particles. Experiments by Elenbaas described by Cobine [6] show that in ares at pressures above $20 \mathrm{~mm} \mathrm{Hg}$, the electron and gas

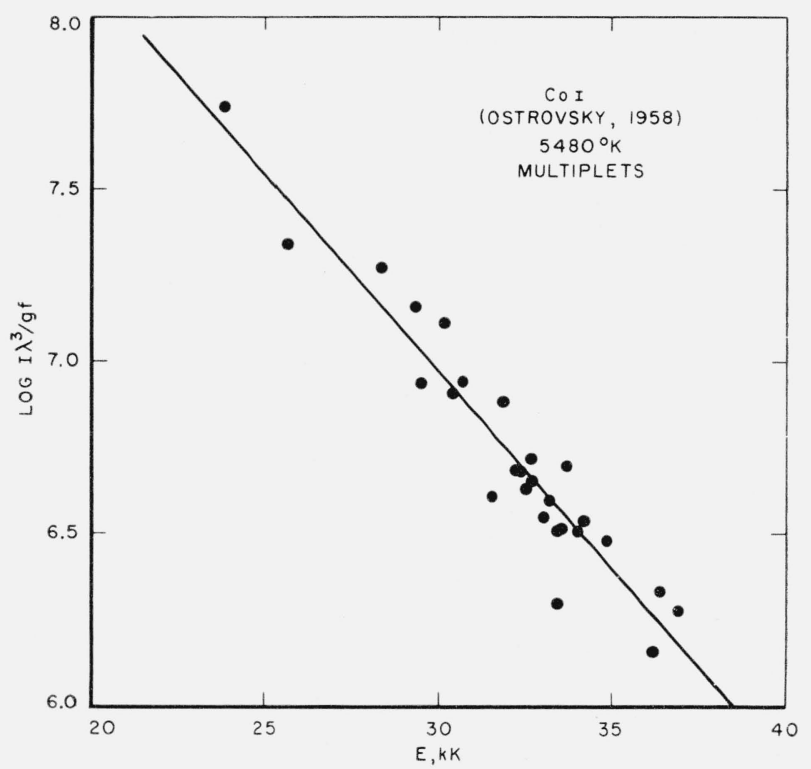

FIgURE 2. Log ratio of intensity $\times \lambda^{3}$ to gf-value for multiplets of Co I in the copper arc plotted versus upper level.

An are temperature of $5480{ }^{\circ} \mathrm{K}$ is derived from the slope of the line of best fit 


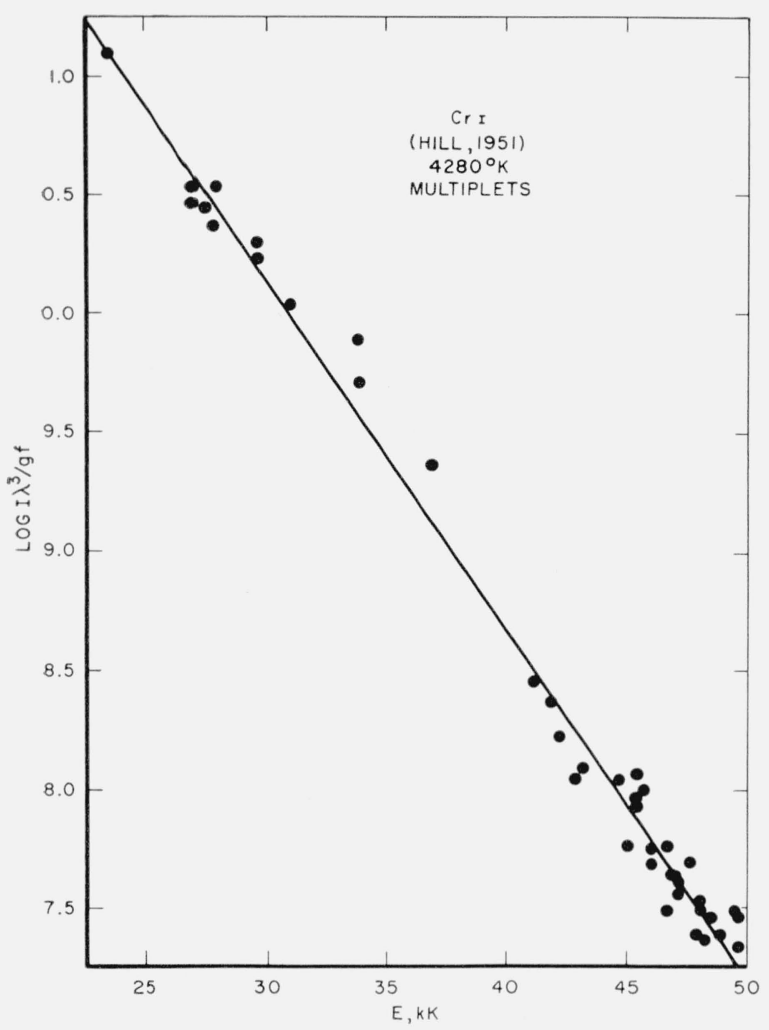

Figure 3. Log ratio of intensity $\times \lambda^{3}$ to gf-value for multiplets of $\mathrm{Cr} \mathrm{I}$ in the copper arc plotted versus upper level.

An are temperature of $4280^{\circ} \mathrm{K}$ is derived from the slope of the line of best fit.

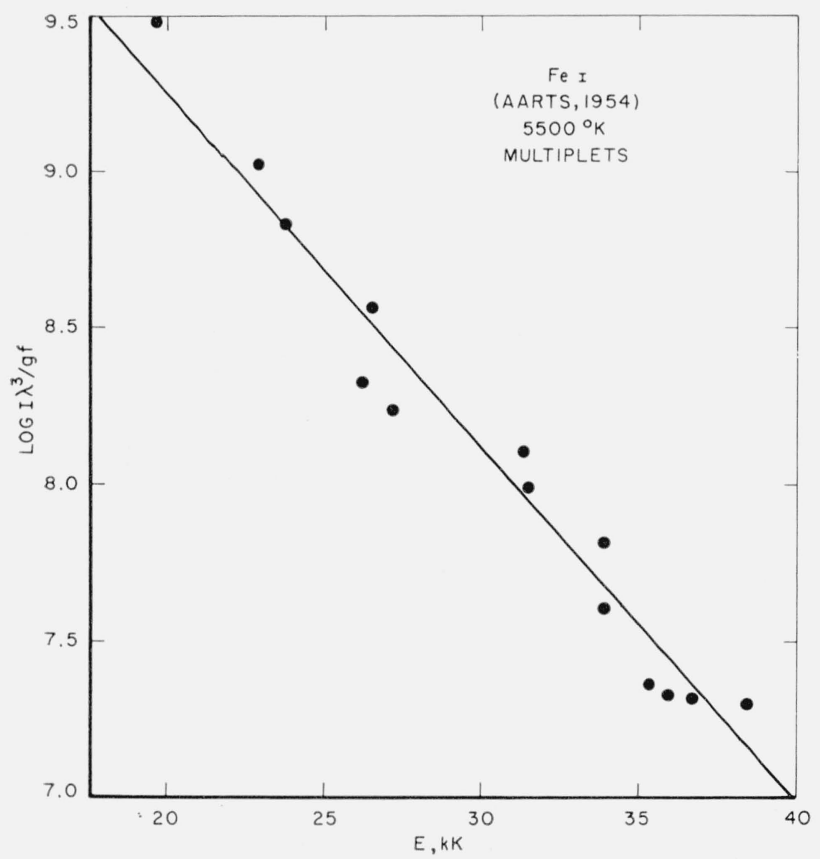

FIguRE 4. Log ratio of intensity $\times \lambda^{3}$ to gf-value for multiplets of $\mathrm{Fe} \mathrm{I}$ in the copper arc plotted versus upper level.

An arc temperature of $5500^{\circ} \mathrm{K}$ is derived from the slope of the line of best fit.

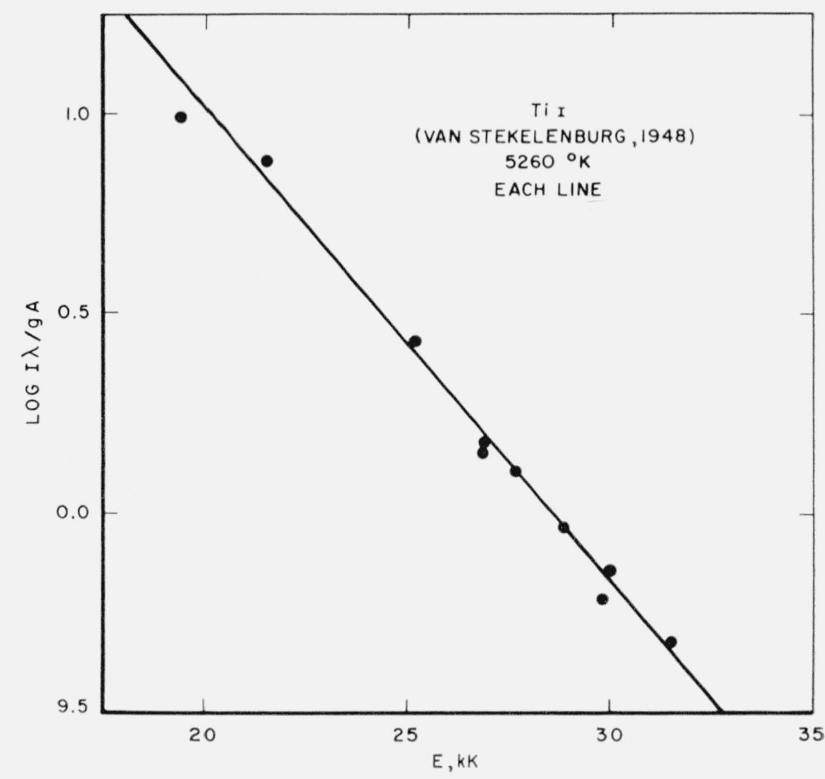

Figure 5. Log ratio of intensity $\times \lambda$ to $g$ A for lines of $\mathrm{Ti}$ I in the copper arc plotted versus upper level.

An are temperature of $5260^{\circ} \mathrm{K}$ is derived from the slope of the line of best fit.

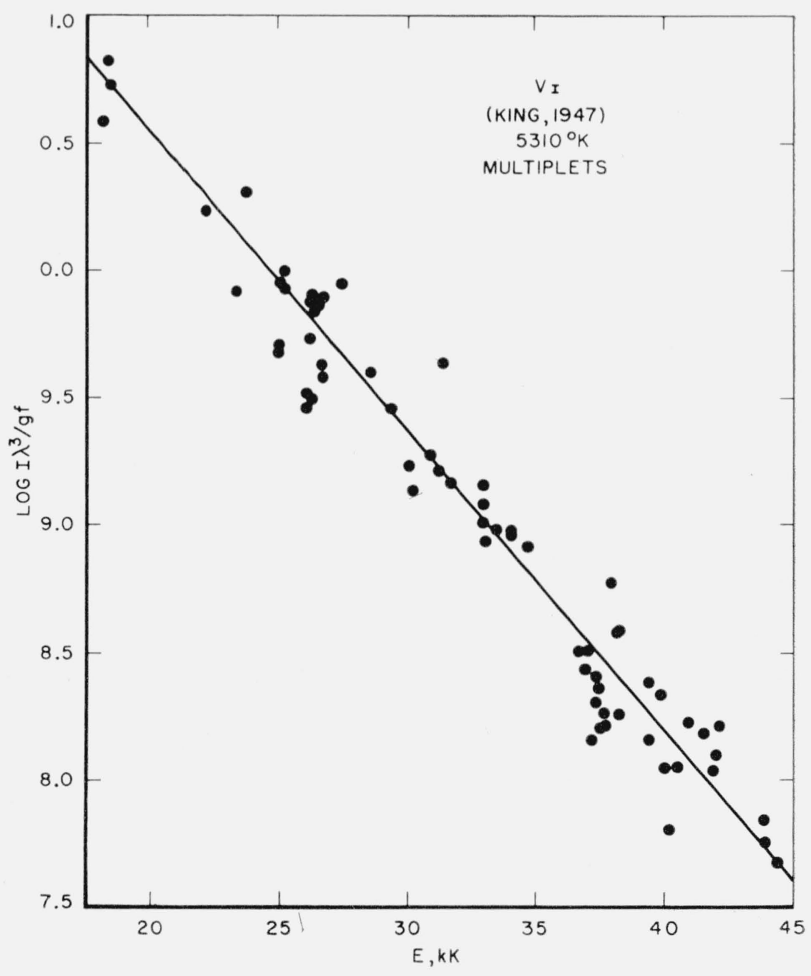

FIgure 6. Log ratio of intensity $\times \lambda^{3}$ to gf-value for multiplets of $\mathrm{V}$ I in the copper arc plotted versus upper level.

An arc temperature of $5310^{\circ} \mathrm{K}$ is derived from the slope of the line of best fit. 


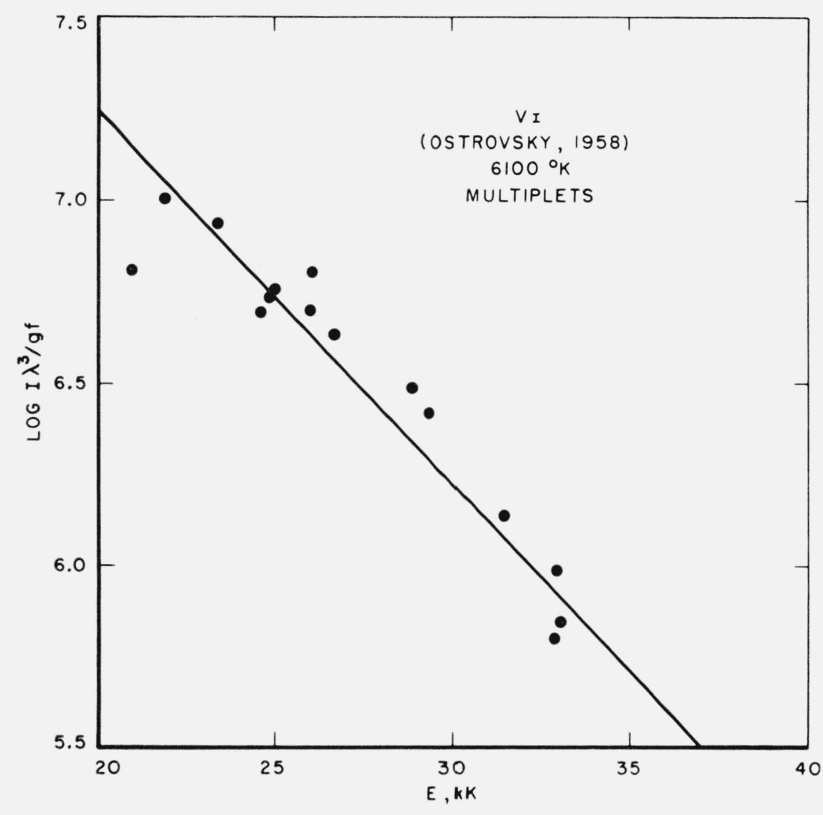

Figure 7. Log ratio of intensity $\times \lambda^{3}$ to gf-value for multiplets of $\mathrm{V}$ I in the copper arc plotted versus upper level.

An are temperature of $6100{ }^{\circ} \mathrm{K}$ is derived from the slope of the line of best fit.

temperatures are equal. Suits [7] has measured the gas temperature and positive ion temperature in arcs at atmospheric pressure and found them equal within an experimental error of $300^{\circ} \mathrm{K}$.

The investigations quoted above are of interest in considering excitation in arcs. However, in this investigation we need not depend on them. The remainder of this paper is devoted to a discussion of graphical evaluations of temperature from eq (5) or (6), using 31 sets of transition probabilities taken from the literature. Examples are shown in figures 1 through 8. The linearity of these plots establishes beyond doubt that the excitation in our arc is described by Boltzmann's law. The fact that the excitation does follow Boltzmann's law enables us to calculate transition probabilities from intensities and conversely. The question of the existence of complete thermodynamical equilibrium per se becomes irrelevant for our purpose.

\section{Choice of Transition Probabilities}

The values of relative transition probabilities available for comparison with our intensities may be divided into four categories: (1) Experimental values based on independent temperature determinations; (2) experimental values based on temperature determinations obtained with data from category (1); (3) values calculated by quantum-mechanical methods (e.g., Hartree-Fock); and (4) values calculated with the approximate theory of Bates and Damgaard. Several trials with data from categories (3) and (4) resulted in plots of eq (7) exhibiting such a large scatter of points that no reasonably reliable temperature could be derived. Allen [8], in a similar investigation, states that use of Bates and Damgaard

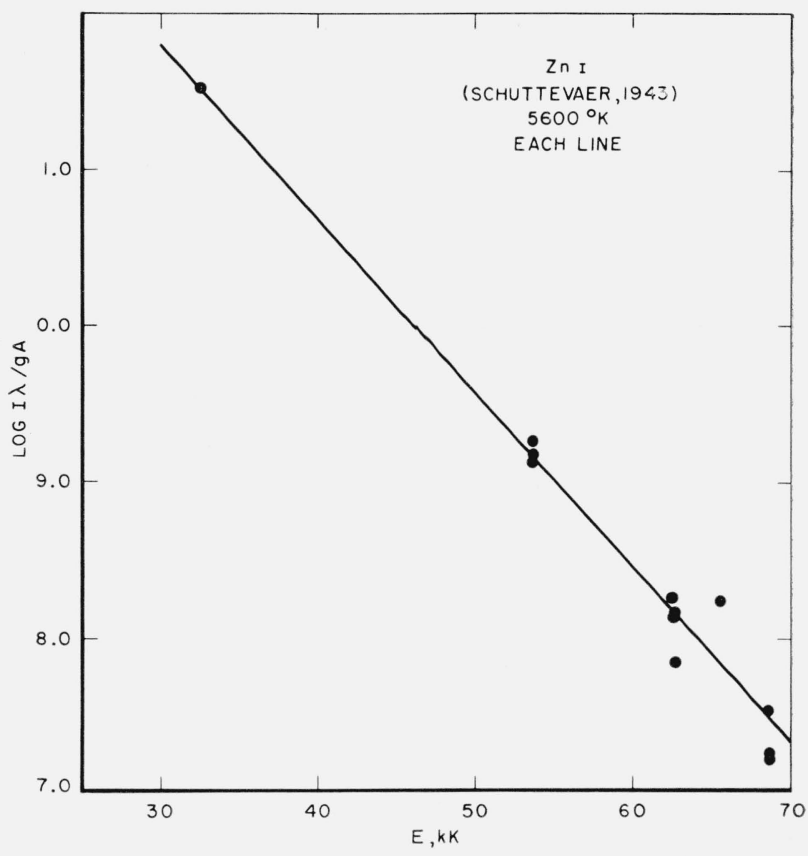

Figure 8. Log ratio of intensity $\times \lambda$ to $g A$ for lines of $\mathrm{Zn}$ I in the copper arc plotted versus upper level.

An arc temperature of $5600^{\circ} \mathrm{K}$ is derived from the slope of the line of best fit.

values leads to impossibly high arc temperatures, particularly in complex spectra. Category (2) is obviously inadmissible for our purposes, since such a set of data would merely duplicate the information from category (1) with which it was calibrated.

We are left with the experimental data of category (1) for our temperature determination. These data are reviewed up to 1954 by R. B. King [9] who noted about 2000 known values. The number has since increased to about 2200 .

\section{Results}

A rather complete search of the published literature on experimental transition probabilities disclosed 31 sets of data suitable for comparison with the intensities in the NBS Tables. All independent sets of data with more than 4 lines in common with those of our tables (and from which temperatures could be derived) were included, with one exception discussed in section 5. The results are summarized in table 1. Column 1 gives the spectrum investigated by the authors in col. 2. The data came from 5 laboratories, indicated in col. 3, and listed below.

Physical Institute of the State University at Leningrad

Physical Laboratory of the University of Utrecht 11 sets

Norman Bridge Laboratory of the California Institute of Technology

Physical Institute, Academy of Sciences USSR, Moscow _..............

Zeeman Laboratory at the University of Amsterdam 10 sets

7 sets 2 sets 1 set 
TABLE 1. Individual determinations of copper arc temperature

\begin{tabular}{|c|c|c|c|c|c|c|c|c|c|c|}
\hline Spectrum & Author & Laboratory & Date & Ref. & Method & $\begin{array}{l}\text { No. of } \\
\text { lines }\end{array}$ & Range of $\mathbf{E}$ & $\triangle \mathrm{E}$ & $\mathrm{T}$ & Dev. \\
\hline $\begin{array}{l}\mathrm{Ag} \text { I } \\
\mathrm{Ba} \text { I } \\
\mathrm{Ba} \text { I } \\
\mathrm{Ca} \text { I } \\
\mathrm{Ca} \text { I } \\
\mathrm{Cd} \text { I }\end{array}$ & $\begin{array}{l}\text { Terpstra et al. } \\
\text { Kruithof } \\
\text { Ostrovsky et al. } \\
\text { Schuttevaer et al. } \\
\text { Olsen et al. } \\
\text { Hengstum et al. }\end{array}$ & $\begin{array}{l}\text { Utrecht } \\
\text { Utrecht } \\
\text { Leningrad } \\
\text { Utrecht } \\
\text { California } \\
\text { Utrecht }\end{array}$ & $\begin{array}{l}1958 \\
1943 \\
1960 \\
1943 \\
1959 \\
1956\end{array}$ & $\begin{array}{l}{[10]} \\
{[11]} \\
{[12]} \\
{[13]} \\
{[14]} \\
{[15]}\end{array}$ & $\begin{array}{l}\text { Are } \\
\text { Are } \\
\text { Hook } \\
\text { Are } \\
\text { Furn. abs. } \\
\text { Are }\end{array}$ & $\begin{array}{r}8 \\
10 \\
54 \\
12 \\
63 \\
15\end{array}$ & $\begin{array}{l}k K \\
43-54 \\
26-35 \\
13-36 \\
32-43 \\
15-49 \\
51-65\end{array}$ & $\begin{array}{r}k K \\
11 \\
9 \\
23 \\
11 \\
34 \\
14\end{array}$ & $\begin{array}{l}{ }^{\circ} K \\
4600 \\
4250 \\
5000 \\
4880 \\
4200 \\
5080\end{array}$ & $\begin{array}{r}{ }^{\circ} K \\
500 \\
850 \\
100 \\
220 \\
900 \\
20\end{array}$ \\
\hline $\begin{array}{l}\text { Cd I } \\
\text { Co I } \\
\text { Co I } \\
\text { Cr I } \\
\text { Fe I }\end{array}$ & $\begin{array}{l}\text { Penkin et al. } \\
\text { King et al. } \\
\text { Ostrovsky et al. } \\
\text { Hill et al. } \\
\text { King et al. } \\
\text { Karter }\end{array}$ & $\begin{array}{l}\text { Leningrad } \\
\text { California } \\
\text { Leningrad } \\
\text { California } \\
\text { California } \\
\text { California }\end{array}$ & $\begin{array}{l}1960 \\
1955 \\
1958 \\
1951 \\
1938 \\
1949\end{array}$ & $\begin{array}{l}{[16]} \\
{[17]} \\
{[18]} \\
{[19]} \\
{[20]} \\
{[21]}\end{array}$ & $\begin{array}{l}\text { Hook and em. } \\
\text { Furn. abs. } \\
\text { Hook } \\
\text { Furn. abs. } \\
\text { Furn. abs. }\end{array}$ & $\begin{array}{r}13 \\
181 \\
79 \\
137 \\
180\end{array}$ & $\begin{array}{l}51-65 \\
24-46 \\
24-37 \\
24-50 \\
19-52\end{array}$ & $\begin{array}{l}14 \\
22 \\
13 \\
26 \\
33\end{array}$ & $\begin{array}{l}4750 \\
5380 \\
5480 \\
4280 \\
4820\end{array}$ & $\begin{array}{l}350 \\
280 \\
380 \\
820 \\
280\end{array}$ \\
\hline $\begin{array}{l}\text { Fe I } \\
\text { Fe I } \\
\text { Fe I } \\
\text { Ga I } \\
\text { Hg I }\end{array}$ & $\begin{array}{l}\text { Sobolev (table } 3 \text { ) } \\
\text { Sobolev (table 5) } \\
\text { Aarts et al. } \\
\text { Ostrovsky et al. } \\
\text { Schouten et al. }\end{array}$ & $\begin{array}{l}\text { Moscow } \\
\text { Moscow } \\
\text { Amsterdam } \\
\text { Leningrad } \\
\text { Utrecht }\end{array}$ & $\begin{array}{l}1943 \\
1943 \\
1954 \\
1958 \\
1943\end{array}$ & $\begin{array}{l}{[22]} \\
{[22]} \\
{[23]} \\
{[24]} \\
{[25]}\end{array}$ & $\begin{array}{l}\text { Are } \\
\text { Are } \\
\text { Furn. em. } \\
\text { Hook } \\
\text { Arc }\end{array}$ & $\begin{array}{r}15 \\
32 \\
59 \\
5 \\
8\end{array}$ & $\begin{array}{l}33-46 \\
27-40 \\
20-38 \\
25-35 \\
62-71\end{array}$ & $\begin{array}{r}13 \\
13 \\
18 \\
10 \\
9\end{array}$ & $\begin{array}{l}4850 \\
5320 \\
5500 \\
5750 \\
6250\end{array}$ & $\begin{array}{r}250 \\
220 \\
400 \\
650 \\
1150\end{array}$ \\
\hline $\begin{array}{l}\text { In I } \\
\text { K I } \\
\text { Mg I } \\
\text { Mn I } \\
\text { Ni I }\end{array}$ & $\begin{array}{l}\text { Ostrovsky et al. } \\
\text { van der Held et al. } \\
\text { Kersten et al. } \\
\text { Ostrovsky et al. } \\
\text { King }\end{array}$ & $\begin{array}{l}\text { Leningrad } \\
\text { Utrecht } \\
\text { Utrecht } \\
\text { Leningrad } \\
\text { California }\end{array}$ & $\begin{array}{l}1958 \\
1936 \\
1941 \\
1957 \\
1948\end{array}$ & $\begin{array}{l}{[24]} \\
{[26]} \\
{[27]} \\
{[28]} \\
{[29]}\end{array}$ & $\begin{array}{l}\text { Hook } \\
\text { Flame } \\
\text { Are } \\
\text { Hook } \\
\text { Furn. abs. }\end{array}$ & $\begin{array}{r}5 \\
6 \\
18 \\
9 \\
89\end{array}$ & $\begin{array}{l}24-33 \\
13-27 \\
41-58 \\
18-36 \\
28-37\end{array}$ & $\begin{array}{r}9 \\
14 \\
17 \\
18 \\
9\end{array}$ & $\begin{array}{l}4510 \\
5100 \\
5780 \\
3900 \\
4660\end{array}$ & $\begin{array}{r}590 \\
0 \\
680 \\
1200 \\
440\end{array}$ \\
\hline $\begin{array}{l}\text { Se I } \\
\text { Sr I } \\
\text { Ti I } \\
\text { Ti I } \\
\text { Ti I }\end{array}$ & $\begin{array}{l}\text { Ostrovsky et al. } \\
\text { Schuttevaer et al. } \\
\text { King et al. } \\
\text { van Stekelenburg et al. } \\
\text { Ostrovsky et al. }\end{array}$ & $\begin{array}{l}\text { Leningrad } \\
\text { Utrecht } \\
\text { California } \\
\text { Utrecht } \\
\text { Leningrad }\end{array}$ & $\begin{array}{l}1957 \\
1943 \\
1938 \\
1918 \\
1956\end{array}$ & $\begin{array}{l}{[30]} \\
{[13]} \\
{[20]} \\
{[31]} \\
{[32]}\end{array}$ & $\begin{array}{l}\text { Hook } \\
\text { Arc } \\
\text { Furn. abs. } \\
\text { Are } \\
\text { Hook }\end{array}$ & $\begin{array}{r}33 \\
8 \\
204 \\
28 \\
56\end{array}$ & $\begin{array}{l}16-33 \\
15-40 \\
19-40 \\
19-32 \\
19-34\end{array}$ & $\begin{array}{l}17 \\
25 \\
21 \\
13 \\
15\end{array}$ & $\begin{array}{l}5100 \\
4410 \\
5080 \\
5260 \\
5400\end{array}$ & $\begin{array}{r}0 \\
690 \\
20 \\
160 \\
300\end{array}$ \\
\hline $\begin{array}{l}\text { Tl I } \\
\text { V I } \\
\text { V I } \\
\text { Zn I } \\
\text { Zn I }\end{array}$ & $\begin{array}{l}\text { Filippov et al. } \\
\text { King } \\
\text { Ostrovsky } \\
\text { Schuttevaer et al. } \\
\text { Penkin et al. }\end{array}$ & $\begin{array}{l}\text { Leningrad } \\
\text { California } \\
\text { Leningrad } \\
\text { Utrecht } \\
\text { Leningrad }\end{array}$ & $\begin{array}{l}1933 \\
1947 \\
1958 \\
1943 \\
1960\end{array}$ & $\begin{array}{l}{[33]} \\
{[34]} \\
{[18]} \\
{[35]} \\
{[16]}\end{array}$ & $\begin{array}{l}\text { Hook } \\
\text { Furn. abs. } \\
\text { Hook } \\
\text { Arc } \\
\text { Hook and em. }\end{array}$ & $\begin{array}{r}5 \\
224 \\
78 \\
12 \\
12\end{array}$ & $\begin{array}{l}26-43 \\
18-42 \\
21-33 \\
31-69 \\
54-68\end{array}$ & $\begin{array}{l}17 \\
24 \\
12 \\
38 \\
14\end{array}$ & $\begin{array}{l}6400 \\
5310 \\
6100 \\
5600 \\
5160\end{array}$ & $\begin{array}{r}1300 \\
210 \\
1000 \\
500 \\
60\end{array}$ \\
\hline
\end{tabular}

The date of publication is given in col. 4 and the reference number, as listed at the end of this paper, in col. 5. The method used in the paper is indicated in col. 6. In general, the several laboratories use different methods. At Leningrad the anomalous dispersion of the vapor in the neighborbood of the absorption lines from a furnace is employed according to the "hook" method of Rogestwensky [36], sometimes with variations. The temperature of the tube furnace is measured with an optical pyrometer. At Utrecht measurements are made usually with the are method originated by Ornstein and his co-workers [5] and carried on by Professor Smit [37]. In that procedure, the temperature is usually measured from the intensity distribution in the $\mathrm{CN}$ bands in the spectrum. The California experiments generally follow the method of total absorption as developed by King and King [38]. The furnace temperature is measured with an optical pyrometer.

The number of spectral lines utilized in each determination is given in col. 7 . The largest numbers are from California. The minimum and maximum values of upper excitation potential and the differences between them are given in cols. 8 and 9 . These determine the range of the abscissae of the plots and thus affect to some extent the precision of the slope determination. The temperature determined from the slope of the plot appears in col. 10 and its deviation from the mean value in col. 11 . The average value of the 31 individual determinations is $5100{ }^{\circ} \mathrm{K}$ and the average deviation is $470{ }^{\circ} \mathrm{K}(9 \%)$. The standard deviation of an individual determination, which is a measure of the scatter of the determinations, is given by

$$
\sigma=\sqrt{\frac{\sum \operatorname{dev}^{2}}{n-1}}
$$

and is equal to $600{ }^{\circ} \mathrm{K}(12 \%)$. The standard deviation of the mean, which measures the precision of the result, is given by

$$
\sigma_{m}=\sqrt{\frac{\sum \operatorname{dev}^{2}}{n(n-1)}}
$$

and is equal to $110{ }^{\circ} \mathrm{K}(2 \%)$. The median value is also $5100^{\circ} \mathrm{K}$.

It is of interest to compare the results from the three major contributors of transition probability data. This is done in table 2. The three mean values agree amongst themselves within their uncertainties. Another test of the data was made by selecting 12 sets of data which, on the basis of small scatter and uniform distribution of the points, and adequate range of $E$, seemed to give promise of better determinations. The average of these 12 is $5000{ }^{\circ} \mathrm{K}$ with an average deviation of $500{ }^{\circ} \mathrm{K}$. These values are not significantly different from the general averages. The above mentioned tests provide some confidence in the adoption of an unweighted mean as the best value for the temperature.

Eight of the plots from which the temperatures were derived are reproduced in the figures. In each figure is given the spectrum, the reference from which the transition probabilities were taken, the temperature derived from the plot and a note whether each point on the plot represents a single spectral line or the average value for a multiplet. 
TABle 2. Comparison of laboratories

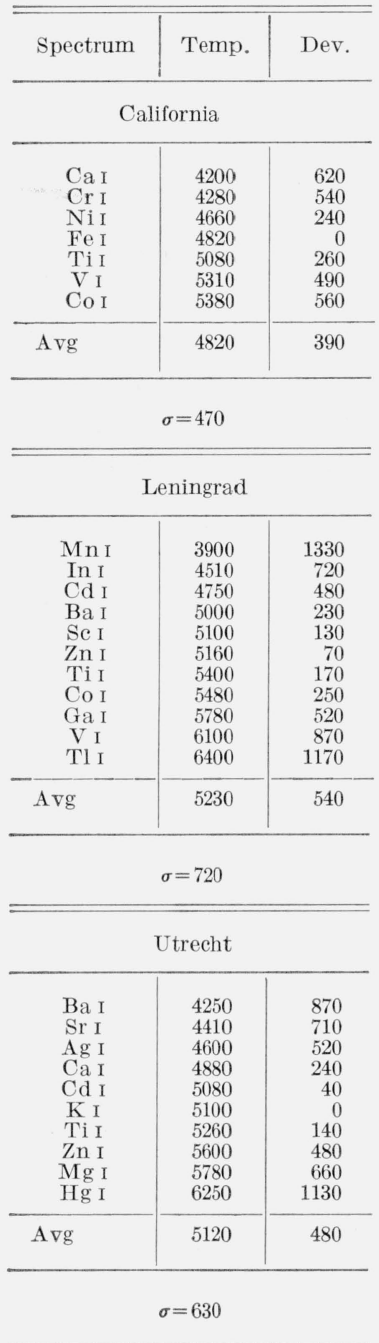

\section{Discussion of Results}

It might not be amiss to discuss briefly the individual determinations. $\mathrm{Ag}$ gave a good plot, but with only a small range of $E$ and a small number of lines. The Leningrad $\mathrm{Ba}$ data are excellent, except for low values of $g f$ for 4132 and 3889 A which were probably caused by the proximity of strong lines at 4130 and $3891 \mathrm{~A}$. The Utrecht Ba plot is good. Both plots of $\mathrm{Cd}$ are good and they agree well. Both Ca plots are excellent; the California one covers an unusually long range of $E$ (see fig. 1). The plot of the Co data from California is long and straight but shows some scatter: the Leningrad one is shorter but with less scatter (see fig. 2). The low temperature which is obtained with the California $\mathrm{Cr}$ data bas been noticed by several other people and is discussed by Goldberg, Muller, and Aller [39]. Otherwise a good plot is obtained (fig. 3). A set of Cr data from Leningrad shows such a large scatter and small range of $E$ that no temperature could be derived [28].
In the California Fe plot, all the lines below $3200 \mathrm{~A}$ stand above the line. These were ignored in deriving the slope. The Moscow Fe data show a rather large scatter but yield satisfactory temperatures. The same paper [22] gives a set of data for $\mathrm{Bi}$, which, although apparently in good order, vields a temperature of $8700^{\circ} \mathrm{K}$, which differs from the general mean by six times the standard deviation and it has been rejected, as noted above. The Amsterdam Fe data form an excellent plot with a good range of $E$ and a small scatter (see fig. 4).

The Ga and In data are deficient in number and involve only resonance lines which are generally subject to various experimental difficulties, but they give a satisfactory plot. The plot for $\mathrm{Hg}$ covers too short a range of $E$ because the NBS intensity of the resonance line was affected by self-absorption and could not be used. $\mathrm{K}$ represents the only data obtained from flames, and, although necessarily deficient in number of lines, yields a satisfactory plot. It involves the resonance lines, which showed no self-absorption in the NBS spectra. The $\mathrm{Mg}$ data show a good distribution and a very small scatter. The $\mathrm{Mg}$ resonance line was omitted because of self-absorption in the NBS line. The Mn resonance lines fall high on the Mn plot, indicating too low a value of $g f$ from the hook method, and they were not used in finding the slope. Ni gives a good plot but with a small range of $E$. As in the case of $\mathrm{Mn}$, the resonance lines of Sc are high on the plot and were ignored in determining the slope. The hook method apparently tends to give low values for the strongest lines. The Utrecht Sr data make a nice plot over a good range of $E$. Another set of $\mathrm{Sr}$ data obtained by Eberhagen at Göttingen [40] by using the Kiel water-arc forms a set of points with too large a scatter to permit a determination of temperature.

Data for Ti are available from three laboratories. The California set has a large number of points well distributed over a long range of $E$ and a very small scatter. A preliminary plot of these data is shown in ref. [1]. The Utrecht data are fewer and have a smaller range, but shown almost no scatter. The maximum vertical deviation of a point from the best line is $0.09 \mathrm{log}$ units which represents a maximum deviation of 23 percent (see fig. 5). The Leningrad data have more points but a considerable scatter. It may be mentioned at this point that Miss Rountree [41] has calculated a temperature for our are from our 'Ti data and King's. Her value is slightly high because she omitted the $\lambda^{3}$ factor of eq (7). The Tl data from Leningrad have been frequently cited in the Russian literature. There are only 5 lines in common with ours. The fact that the temperature derived from these data shows the maximum deviation in the group of 31 values may arise from the location of 4 of the 5 lines in the short wavelength regions below $2800 \mathrm{~A}$ where the accuracy of the intensities declines. The $\mathrm{V}$ data from California have the largest number of lines in the group and the plot shows a moderate scatter of points well distributed over a long range of $E$, permitting an accurate determination of $T$. It shows no suggestion of curvature, indicating strict adherence to Boltz- 
mann's law (see fig. 6). The Leningrad data cover a shorter range of $E$ (see fig. 7). The Utrecht data for $\mathrm{Zn}$ cover the longest range of $E$ of the whole group and give a very straight plot (see fig. 8). The Leningrad data omit the intersystem line at $3075 \mathrm{~A}$ and so have a more restricted range of $E$.

Taken as a whole, the results exhibit a nearly normal (Gaussian) distribution of values (see table $3)$. Consideration of the results in table 1 suggests that the effective temperature of the copper arc is substantially constant and that the variations arise from systematic errors in the various sets of transition probabilities. For example, the two sets of $g f$-values for $V$ I exbibited in figures 6 and 7 are compared with the same intensity numbers in each case. The temperature difference of $780{ }^{\circ} \mathrm{K}$ between the values from each plot can arise only from systematic errors inherent in the two sets of $g f$-values. Similarly, the transition probabilities of van Hengstum and Smit [15] for Cd I are systematically smaller relative to those of Penkin and Redko [16] at the larger values of $E$, so although the identical NBS intensity numbers are used, the two plots yield temperatures which differ by $330^{\circ} \mathrm{K}$. The diversity of methods represented and the independent nature of the laboratories leads us to suppose that these systematic errors have offset one another to some extent in contributing to the general average value.

Various correlation plots have been made to determine other systematic influences on the derived temperatures. There appears to be no correlation with the number of lines used, with atomic number, with range of $E$ (abscissae of the plots), with magnitude of $E$, nor with ionization potential.

TABle 3. Distribution of individual temperature determinations about the mean, in intervals of $\sigma$.

\begin{tabular}{|c|c|c|c|c|c|c|}
\hline Interval . . & $\begin{array}{l}3300- \\
3900\end{array}$ & $\begin{array}{c}3900- \\
4500\end{array}$ & $\begin{array}{c}4500- \\
5100\end{array}$ & $\begin{array}{l}5100- \\
5700\end{array}$ & $\begin{array}{l}5700- \\
6300\end{array}$ & $\begin{array}{l}6300- \\
6900\end{array}$ \\
\hline $\begin{array}{l}\text { Individual } \\
\text { determinations }\end{array}$ & 3900 & $\begin{array}{l}4200 \\
4250 \\
4280 \\
4410\end{array}$ & $\begin{array}{l}4510 \\
4600 \\
4660 \\
4750 \\
4820 \\
4850 \\
4880 \\
5000 \\
5080 \\
5080 \\
5100\end{array}$ & $\begin{array}{l}5100 \\
5160 \\
5260 \\
5310 \\
5320 \\
5380 \\
5400 \\
5480 \\
5500 \\
5600\end{array}$ & $\begin{array}{l}5750 \\
5780 \\
6100 \\
6250\end{array}$ & 6400 \\
\hline $\begin{array}{l}\text { Observed fraction } \ldots . . . \\
\text { Expected (Gaussian) }\end{array}$ & $\begin{array}{r}0.03 \\
.02\end{array}$ & $\begin{array}{r}0.13 \\
.14\end{array}$ & $\begin{array}{r}0.36 \\
.34\end{array}$ & $\begin{array}{r}0.32 \\
.34\end{array}$ & $\begin{array}{r}0.13 \\
.14\end{array}$ & $\begin{array}{r}0.03 \\
.02\end{array}$ \\
\hline
\end{tabular}

\section{Effect of Uncertainty in Temperature on Uncertainty in Derived Transition Probability}

The purpose of determining the best value of the temperature of the copper are is to enable us to calculate values of $g A$ or $g f$ from the intensities of the classified lines in the NBS Tables of Spectral-line Intensities. We must find out how the uncertainty of the value of $T$ will influence the uncertainty of the $g A$ or $g f$.
If we differentiate eq (3) with respect to $T$ and divide the result by eq (3) we have

$$
\frac{d(g A)}{g A}=-\frac{E}{k T} \frac{d T}{T}
$$

Introducing numerical values we find

$$
\frac{d(g A)}{g A}=-\frac{E}{3.54} \frac{d T}{T}
$$

Now if $\frac{d T}{T}$ is 2 percent, then

$$
\frac{d(g A)}{g A}=-0.00565 \mathrm{E} \text {. }
$$

Similarly

$$
\frac{d(g f)}{g f}=-0.00565 \mathrm{E} \text {. }
$$

The magnitude of the error for values of the upper level from 10 to 100 kilokaysers is given in table 4, assuming a temperature of $5100{ }^{\circ} \mathrm{K}$ and an uncertainty in the temperature of 2 percent. Most of the lines in the NBS tables have upper levels less than $50 \mathrm{kK}$, so most of the errors introduced by the temperature error will be less than 30 percent. This is about the same as the errors in the intensity numbers themselves.

TABLE 4. Error in gf of $g A$ corresponding to a 2 percent error

\begin{tabular}{c|c} 
in T at $5100^{\circ} \mathrm{K}$ \\
\hline \hline$E$ in kK & $\begin{array}{c}\text { \% error in } \\
g f \text { or } g \text { A }\end{array}$ \\
\hline- & \\
10 & 6 \\
20 & 11 \\
30 & 17 \\
40 & 23 \\
50 & 28 \\
60 & 34 \\
70 & 40 \\
90 & 45 \\
90 & 51 \\
100 & 56 \\
\hline
\end{tabular}

\section{Conclusion}

A temperature for the copper are in which the intensities published in the NBS Tables of Spectralline Intensities [1] were measured has been determined. Comparison of NBS intensities with 1650 published transition probabilities for 20 different spectra yields the value

$$
5100 \pm 110{ }^{\circ} \mathrm{K} .
$$

With this parameter, relative transition probabilities for the 25,000 classified lines in the NBS Tables can be computed.

Further studies are in progress to determine the state of ionization of each element in the arc. This will allow the relative values for each spectrum to be adjusted to the same scale. It may then be possible to calibrate the scale on an absolute basis as Allen 
has done [42]. All the pertinent data for the 25,000 lines are on punched cards and the computation can be performed very quickly, once the proper parameters and factors have been determined.

The author acknowledges the kind encouragement of W. F. Meggers and the helpful assistance of K. G. Kessler. The idea for this work came during a staff meeting lecture given by $\mathrm{H}$. P. Broida many years ago. The work was greatly facilitated by the new NBS Data Center on Atomic Physics and its curator, Miss Barbara Glennon.

\section{References}

[1] W. F. Meggers, C. H. Corliss, and B. F. Scribner, Tables of Spectral-line Intensities, NBS Monograph 32 (1961), (U.S. Government Printing Office, Washington, D.C.)

[2] A. Einstein, Phys. Z. 18, 121 (1917).

[3] Transactions of the Joint Commission for Spectroscopy, J. Opt. Soc. Am. 43, 410 (1953).

[4] R. Ladenburg, Z. Physik 4, 451 (1921).

[5] L. S. Ornstein and H. Brinkman, Physica 1, 797 (1934).

[6] J. D. Cobine, Gaseous Conductors, p. 290, Dover Publications, New York (1958).

[7] C. G. Suits, Physics 6, 190 and 315 (1935).

[8] C. W. Allen and A. S. Asaad, Mon. Not. Roy. Astronom. Soc. 115, 571 (1955).

[9] R. B. King, Proc. of Conf. on Stellar Atmospheres, Indiana Univ. (1954).

[10] J. Terpstra and J. A. Smit, Physica 24, 937 (1958).

[11] A. M. Kruithof, Physica 10, 493 (1943).

[12] Y. I. Ostrovsky and N. P. Penkin, Optics and Spectroscopy 9, 371 (1960).

[13] J. W. Schuttevaer, M. J. de Bont, and T. H. van den Broek, Physica 10, 544 (1943).

[14] K. H. Olsen, P. M. Routly, and R. B. King, Astrophys. J. 130, 688 (1959).
[15] J. P. A. van Hengstum and J. A. Smit, Physica 22, 86 (1956).

[16] N. P. Penkin and T. P. Red'ko, Opties and Spectroscopy 9, 360 (1960).

[17] R. B. King, B. Parnes, M. Davies, and K. H. Olsen, J. Opt. Soc. Am. 45, 350 (1955).

[18] Y. I. Ostrovsky and N. P. Penkin, Optika i Spektroskopiya 5, 345 (1958).

[19] A. J. Hill and R. B. King, J. Opt. Soc. Am. 41, 315 (1951).

[20] R. B. King and A. S. King, Astrophys. J. 87, 24 (1938).

[21] W. W. Carter, Phys. Rev. z6, 962 (1949).

[22] N. N. Sobolev, J. Exp. Theoret. Phys. 13, 131 (1943).

[23] J. Aarts, D. Harting, and C. J. Bakker, Physica 20, 1250 (1954).

[24] Y. I. Ostrovsky and N. P. Penkin, Optika i Spektroskopiya 4, 719 (1958).

[25] J. W. Schouten and J. A. Smit, Physica 10, 661 (1943).

[26] E. F. M. van der Held and J. H. Heierman, Physica 3, 31 (1936).

[27] J. A. H. Kersten and L. S. Ornstein, Physica 8, 1124 (1941).

[28] Y. I. Ostrovsky and N. P. Penkin, Optika i Spektroskopiya 3, 193 (1957).

[29] R. B. King, Astrophys. J. 108, 87 (1948).

[30] Y. I. Ostrovsky and N. P. Penkin, Optika i Spektroskopiya 3, 391 (1957).

[31] L. H. M. van Stekelenburg and J. A. Smit, Physica 14, 185 (1948).

[32] Y. I. Ostrovsky, G. F. Parchevsky, and N. P. Penkin, Optika i Spektroskopiya 1, 821 (1956).

[33] A. Filippov and W. Prokofiev, Z. Physik 85, 647 (1933).

[34] R. B. King, Astrophys. J. 105, 376 (1947).

[35] J. W. Schuttevaer and J. A. Smit, Physica 10, 502 (1943).

[36] D. S. Rogestwensky and N. P. Penkin, J. Phys. U.S.S.R. 5, 319 (1941).

[37] J. A. Smit, Physica 12, 683 (1946).

[38] R. B. King and A. S. King, Astrophys. J. 82, 377 (1935).

[39] L. Goldberg, E. A. Muller, and L. H. Aller, Astrophys. J. Supplement No. 45 5, 1 (1960).

[40] A. Eberhagen, Z. Physik 143, 392 (1955).

[41] J. C. Rountree, Annales d'Astrophysique 23, 633 (1960).

[42] C. W. Allen and A. S. Asaad, Mon. Not. Roy. Astron. Soc. 117, 36 (1957); C. W. Allen, ibid. 11\%, 622 (1957); C. W. Allen, ibid, 121, 299 (1960).

(Paper 66A1-136) 